\title{
PERHITUNGAN PREMI ASURANSI JOINT LIFE DENGAN MODEL VASICEK DAN CIR
}

\author{
I Made Wahyu Wiguna $^{1 \S}$, Ketut Jayanegara ${ }^{2}$, I Nyoman Widana ${ }^{3}$ \\ ${ }^{1}$ Program Studi Matematika, Fakultas MIPA - Universitas Udayana [Email: madewahyuhap28@gmail.com] \\ ${ }^{2}$ Program Studi Matematika, Fakultas MIPA - Universitas Udayana [Email: ktjayanegara@unud.ac.id] \\ ${ }^{3}$ Program Studi Matematika, Fakultas MIPA - Universitas Udayana [Email: nwidana@unud.ac.id] \\ ${ }^{\S}$ Corresponding Author
}

\begin{abstract}
Premium is a sum of money that must be paid by insurance participants to insurance company, based on insurance contract. Premium payment are affected by interest rates. The interest rates change according to stochastic process. The purpose of this work is to calculate the price of joint life insurance premiums with Vasicek and CIR models. The price of a joint life insurance premium with Vasicek and CIR models, at the age of the insured 35 and 30 years has increased until the last year of the contract. The price of a joint life insurance premium with Vasicek model is more expensive than the premium price using CIR model.
\end{abstract}

Keywords: premium payments, interest rates, Vasicek and CIR.

\section{PENDAHULUAN}

Secara konseptual asuransi merupakan pemindahan risiko dimana pihak tertanggung mengikatkan diri dalam bentuk kontrak polis kepada perusahaan asuransi Futami, (1993). Setiap peserta asuransi diwajibkan membayar premi kepada pihak perusahaan asuransi. Premi merupakan sejumlah uang yang wajib dibayarkan oleh peserta asuransi kepada perusahaan asuransi sesuai dengan kontrak yang telah disetujui.

Nilai premi bersih dipengaruhi oleh tingkat mortalitas dan tingkat suku bunga. Terdapat dua jenis suku bunga yaitu, suku bunga tetap dan suku bunga berubah secara tidak menentu (stokastik). Model tingkat suku bunga stokastik diantaranya menggunakan model Vasicek dan Cok Ingersol Ros (CIR).

Penelitian ini bertujuan menghitung nilai premi asuransi jiwa joint life dengan model Vasicek dan CIR. Peserta yang mengikuti asuransi yaitu dua orang berusia $x$ dan $y$ tahun dengan lama kontrak selama 10 tahun dan uang pertanggungan Rp. 100.000.000,00.

Menurut Futami (1993), tabel mortalitas merupakan tabel observasi mengenai peluang tingkat kematian berdasarkan kelompok umur. Fungsi-fungsi utama dalam tabel mortalitas adalah:

$$
\begin{aligned}
l_{x+1} & =l_{x}-d_{x} \\
q_{x} & =\frac{d_{x}}{l_{x}} \\
p_{x} & =1-q_{x}
\end{aligned}
$$

dengan $l_{x}$ merupakan banyaknya individu yang berhasil mencapai usia tepat $x$ tahun, $d_{x}$ merupakan banyaknya individu yang meninggal antara umur $x$ tahun sampai $x+1$ tahun, $q_{x}$ merupakan peluang individu berumur $x$ meninggal dalam kurun waktu 1 tahun, dan $p_{x}$ merupakan peluang individu berumur $x$ mencapai umur $x+1$ tahun.

Fungsi gabungan yang menyatakan banyaknya orang berusia $x$ tahun yang masih hidup dikalikan dengan banyaknya orang berumur $y$ tahun yang masih hidup dinotasikan dengan $l_{x y}$. Peluang orang berusia $x$ tahun dan $y$ tahun akan tetap hidup selama 1 tahun dinotasikan dengan $p_{x y}$. Peluang orang berusia $x$ tahun dan $y$ tahun akan tetap hidup selama $t$ tahun dinotasikan dengan ${ }_{t} p_{x y}$ dan dirumuskan sebagai berikut:

$$
\begin{gathered}
l_{x y}=l_{x} l_{y} \\
p_{x y}=p_{x} p_{y}=\frac{l_{x+1}}{l_{x}} \frac{l_{y+1}}{l_{y}}=\frac{l_{x y+1}}{l_{x y}} \\
{ }_{t} p_{x y}={ }_{t} p_{x}{ }_{t} p_{y}=\frac{l_{x+t}}{l_{x}} \frac{l_{y+t}}{l_{y}}=\frac{l_{x y+t}}{l_{x y}}
\end{gathered}
$$


Peluang salah satu diantara $x$ dan $y$ meninggal dalam jangka waktu 1 tahun dinotasikan dengan $q_{x y}$ dan dirumuskan sebagai berikut:

$$
q_{x y}=1-p_{x y}=\frac{l_{x y}-l_{x y+1}}{l_{x y}}
$$

Model Vasicek merupakan suatu model suku bunga stokastik yang mempunyai ciri khusus yaitu tingkat suku bunga akan cenderung kembali ke tingkat suku bunga rata-rata setelah mengalami penurunan atau peningkatan yang didefinisikan sebagai (Zeytun, 2007):

$$
\begin{gathered}
d r(t)=\kappa[\theta-r(t)] d t+\sigma d W(t) \\
r(0)=r_{0}
\end{gathered}
$$

Dengan menggunakan persamaan differensial parsial diperoleh solusi dari persamaan (1) adalah:

$$
\begin{aligned}
& r(t)=r_{o} e^{-k t}+\theta\left(1-e^{-k t}\right) \\
& +\sigma \int_{o}^{t} e^{-k(t-u)} d W(u)
\end{aligned}
$$

Dari persamaan (2) di tentukan ekspektasi dan variansi yaitu (Bayazit, 2004)

$$
\begin{gathered}
\mathrm{E}(\mathrm{r}(\mathrm{t}))=\mathrm{r}_{\mathrm{o}} \mathrm{e}^{-\mathrm{kt}}+\theta\left(1-\mathrm{e}^{-\mathrm{kt}}\right) \\
\operatorname{Var}(\mathrm{r}(\mathrm{t}))=\frac{\sigma^{2}}{2 \mathrm{k}}\left(1-\mathrm{e}^{-2 \mathrm{kt}}\right)
\end{gathered}
$$

Misalkan $P_{1}(t)$ menyatakan ekspektasi dari nilai tunai pembayaran sebesar 1 unit pada saat $t$ untuk tingkat suku bunga yang mengikuti model Vasicek Hull, (2003).

$$
\begin{array}{r}
P_{1}(t)=\exp \left((B(t)-t)\left(\theta-\frac{\sigma^{2}}{2 k^{2}}\right)\right. \\
\left.-\frac{\sigma^{2} B(t)^{2}}{4 k}-r(0) B(t)\right)
\end{array}
$$

dengan $(t)=\frac{1-\exp (-k t)}{k} ; B(t)$. Nilai awal pada tahap estimasi parameter didapatkan dari metode OLS(Ordinary Least Square). Metode OLS adalah metode estimasi dalam ilmu statistika yang meminimalkan jumlahan kuadrat dari eror. Persamaan (4) diubah menjadi bentuk

$$
r_{t+1}-r_{t}=k\left(\theta-r_{t}\right) \Delta t+\sigma \varepsilon_{t}
$$

dengan $\varepsilon_{t} \sim N(0,1)$. Untuk menggunakan OLS, persamaan (5) ditranformasi ke bentuk:

$$
r_{t+1}-r_{t}=k \theta \Delta t-k r_{t} \Delta t+\sigma \varepsilon_{t} \quad(6)
$$

dengan meminimalkan jumlahnya kuadrat dari bagian eror $\sum_{t=1}^{n-1}\left(\sigma \varepsilon_{t}\right)^{2}$ terhadap $\widehat{K} \operatorname{dan} \theta$ akan mendapatkan estimator untuk $\widehat{K}$ dan $\hat{\theta}$ sebagai berikut:

$$
\widehat{K}=\frac{n^{2}-2 n+1+U_{2} U_{3}-U_{1} U_{3}-(n-1) U_{4}}{\left(n^{2}-2 n+1-U_{3}\right) \Delta t}
$$

$$
\hat{\theta}=\frac{(n-1) U_{2}-U_{4} U_{1}}{\left(n^{2}-2 n+1+U_{2} U_{3}-U_{1} U_{3}-(n-1) U_{4}\right)}
$$

dengan $U_{1}=\sum_{t=1}^{n-1} r t, \quad U_{2}=\sum_{t=1}^{n-1} r_{t+1}, \quad U_{3}=$ $\sum_{t=1}^{n-1} \frac{1}{r_{t}}$, dan $U_{4}=\sum_{t=1}^{n-1} \frac{r_{t+1}}{r_{t}}$

Dan estimator untuk $\sigma$ adalah Mariana dkk, (2015):

$$
\sigma=\sqrt{\frac{1}{n-2} \sum_{t=1}^{n-1}\left(\frac{\left(r_{t+1}-r_{t}\right.}{\sqrt{r_{t}}}-\frac{\hat{0}}{\sqrt{r_{t}}}+\check{\mathrm{K}} \sqrt{r_{t}}\right)}
$$

Model CIR menjamin tingkat suku bunga bernilai positif dan memiliki sifat mean reversion atau mempunyai kecendrungan kembali menuju rata - rata. Bentuk dari model CIR adalah. Cox \& Ross, (1985)

$$
d r(t)=k(\theta-r(t)) d t+\sigma \sqrt{r(t)} d W(t)(10)
$$

Dengan menggunakan formula itu didapatkan penyelesaian model $C I R$ sebagai berikut:

$$
\begin{gathered}
r(t+1)=\theta\left(1-e^{k \Delta t}\right)+e^{-k \Delta t} r(t) \\
+\in(t+1)
\end{gathered}
$$

dengan

$$
\begin{aligned}
\epsilon(t+1)=\int_{t}^{t+1} \sigma e^{-k(t+1-u)} \\
\\
\times \sqrt{r(u)} d W(u)
\end{aligned}
$$

Setelah mendapatkan penyelesaian dari model CIR, selanjutnya dicari rata-rata dan varians. Dengan menghitung rata-rata model $C I R$, bisa dibuktikan sifat mean reversion dari model CIR. Rata-rata bisa didapat dengan menghitung ekspektasinya

$$
E[r(t)]=e^{-k t} r(0)+\theta\left(1-e^{-k t}\right)
$$

Selanjutnya akan dihitung varians dari model CIR. Dengan terlebih dahulu menghitung $E\left[r^{2}(t)\right]$ dan $(E[r(t)])^{2}$ maka bisa dihitung varians dari suku bunga model $C I R$.

$$
\begin{array}{r}
\operatorname{Var}(r(t))=E\left[r^{2}(t)\right]-(E[r(t)])^{2} \\
=r(0)\left(\frac{\sigma^{2}}{k}\right)\left(e^{-k t}-e^{-2 k t}\right) \\
+\theta\left(\frac{\sigma^{2}}{2 k}\right)\left(1-e^{-k t}\right)^{2}
\end{array}
$$

Sudah didapatkan penyelesaikan mean dan varians dari model $C I R$. misal $p_{2}(t)$ menyatakan ekspetasi dari nilai tunai pembayaran sebesar 1 unit pada saat $t$ untuk tingkat suku bunga yang mengikuti model CIR Hull, (2003).

$p_{2}(t)=\left(\frac{2 d \exp \left(\frac{k+d}{2} t\right)}{\exp (t d)(k+d)+d-k}\right)^{\frac{2 k \theta}{\sigma^{2}}}$ 


$$
\times \exp \left(-\frac{2 r(0)(\exp (t d)-1)}{\exp (t d)(k+d)+d-k}\right)
$$

Nilai awal pada tahap estimasi parameter didapatkan dari metode OLS(Ordinary least square) persamaan (14) diubah menjadi bentuk:

$$
r_{t+1}-r_{t}=k\left(\theta-r_{t}\right) \Delta t+\sigma \sqrt{r_{t}} \varepsilon_{t}
$$

dengan $\varepsilon_{t} \sim N(0,1)$. Untuk menggunakan OLS, persamaan (15) ditransformasi ke bentuk:

$$
\frac{\left(r_{t+1}-r_{t}\right)}{\sqrt{r_{t}}}=\frac{k \theta \Delta t}{\sqrt{r_{t}}}-k \sqrt{r_{t}} \Delta t+\sigma \varepsilon_{t}
$$

Nilai tunai manfaat model Vasicek dan model CIR dihitung menggunakan persamaan sebagai berikut:

$$
A_{x y: n}^{1}=\sum_{k=0}^{n-1} P(k+1)\left({ }_{k} p_{x y}-{ }_{k+1} p_{x y}\right)
$$

Nilai tunai anuitas model Vasicek dan model $C I R$ dihitung menggunakan persamaan sebagai berikut:

$$
\ddot{a}_{x y: n}=\sum_{k=0}^{n-1} P(k)_{k} p_{x y}
$$

Perhitungan nilai Premi Asuransi Joint Life dengan Model Vasicek dan CIR dihitung menggunakan persamaan sebagai berikut:

$$
P=\frac{A_{x y: n}^{1}}{\ddot{a}_{x y: n}}
$$

\section{METODE PENELITIAN}

Penelitian ini menentukan nilai premi asuransi jiwa joint life menggunakan tingkat suku bunga Vasicek dan CIR. Adapun langkahlangkah yang dilakukan dalam penelitian ini adalah:

1. Menentukan estimasi parameter untuk suku bunga Vasicek dan CIR

2. Menghitung suku bunga Vasicek dan CIR.

3. Membuat nilai tabel mortalitas joint life menggunakan Tabel Mortalitas Indonesia 2011.

4. Menghitung nilai premi Vasicek dan CIR pada asuransi joint life.

5. Menginterpretasikan hasil.

\section{HASIL DAN PEMBAHASAN}

\subsection{Estimasi Paramater Suku Bunga Vasicek dan CIR}

Estimasi parameter suku bunga Vasicek dan $C I R$ dicari menggunakan data suku bunga bulanan Bank Indonesia pada periode Juni 2013 - Juli 2016 seperti terlampir (Lampiran 1).
Sebelum mencari nilai kappa, teta, dan zigma, terlebih dahulu mencari $\sum_{t=1}^{39} r_{t}, \quad \sum_{t=1}^{39} \frac{1}{r_{t}}$, $\sum_{t=1}^{39} \frac{r_{t+1}}{r_{t}}$, dan $\sum_{t=1}^{39} r_{t}+1$ sebagai berikut:

$$
\begin{aligned}
\sum_{t=1}^{39} r_{t} & =r_{1}+r_{2}+\ldots+r_{39} \\
& =0,06+0,065+\ldots+0,0675 \\
& =2,85 \\
\sum_{t=1}^{39} \frac{1}{r_{t}} & =\frac{1}{r_{1}}+\frac{1}{r_{2}}+\cdots+\frac{1}{r_{39}} \\
= & \frac{1}{0,06}+\frac{1}{0,065}+\ldots+\frac{1}{0,0675} \\
= & 16,66+15,38+\cdots+14,81 \\
= & 535,3556 \\
\sum_{t=1}^{39} \frac{r_{t+1}}{r_{t}} & =\frac{r_{2}}{r_{1}}+\frac{r_{3}}{r_{2}}+\cdots+\frac{r_{40}}{r_{39}} \\
& =\frac{0,065}{0,06}+\frac{0,065}{0,065}+\cdots+\frac{0,065}{0,075} \\
& =1,08+1+\cdots+0,96 \\
& =39,09096 \\
\sum_{t=1}^{39} r_{t+1} & =r_{2}+r_{3}+\ldots+r_{40} \\
& =0,065+0,065+\cdots+0,065 \\
& =2,855
\end{aligned}
$$

Setelah memperoleh nilai tersebut, nilai kappa, teta, dan sigma dapat dihitung sebagai berikut:

$$
\begin{aligned}
\widehat{\mathrm{K}} & =\left(40^{2}-2 \cdot 40+1+2,855 \cdot 535,3556-\right. \\
& 2,85 \cdot 535,3556-39 \cdot 39,09096) \\
& \times \frac{1}{\left(40^{2}+2 \cdot 40+1-535,3556\right) \cdot \frac{1}{2}} \\
& =2,193516 \\
\widehat{\theta} & =\frac{-0,06424}{-0,87066} \\
& =0,073778 \\
\sigma & =\sqrt{\frac{1}{38}(0,0658+\cdots+0,078212)} \\
= & 0,325004
\end{aligned}
$$

\subsection{Menghitung Suku Bunga Vasicek dan CIR}

Setelah memperoleh estimasi parameter dari suku bunga vasicek dan $C I R$, dilanjutkan dengan menghitung suku bunga vasicek dan $C I R$ dengan menggunakan parameter yang sudah diperoleh sebelumnya, yaitu sebagai berikut: $r(t)=r_{o} e^{-k t}+\theta\left(1-e^{-k t}\right)$ 


$$
\begin{aligned}
& +\sigma \int_{o}^{t} e^{-k(t-u)} d W(u) \\
r(1)= & 0,065 \cdot e^{-2,193516.1} \\
& +0,073778\left(1-e^{-2,193516.1}\right) \\
& +0,325004 \int_{0}^{1} e^{-2,193516 \cdot(1-u)} d W(u) \\
r(1)= & 0,062863308
\end{aligned}
$$

Selanjutnya, menghitung suku bunga $C I R$ yaitu sebagai berikut:

$$
\begin{aligned}
r(t+1)= & e^{-k \Delta t} r(t)+\theta\left(1-e^{-k \Delta t}\right) \\
& +\int_{t}^{t+1} \sigma e^{k(t+1-u)} \sqrt{r(u)} d W(u) \\
r(1)= & e^{-2,193516.1} \cdot 0,065 \\
& +0,073778\left(1-e^{-2,193516.1}\right) \\
& +\int_{0}^{1}\left(0,325004 \cdot e^{-2,193516(1-u)}\right. \\
& \times \sqrt{r(u)} d W(u) \\
= & 0,06506093
\end{aligned}
$$

hasil perhitungan disajikan pada tabel 1 .

Tabel 1. Suku Bunga Vasicek dan CIR.

\begin{tabular}{|l|l|l|}
\hline $\boldsymbol{r}(\boldsymbol{t})$ & Bunga Vasicek & Bunga CIR \\
\hline 1 & 0,062863308 & 0,06506093 \\
\hline 2 & 0,075257336 & 0,073618098 \\
\hline 3 & 0,076510695 & 0,074480968 \\
\hline 4 & 0,064237383 & 0,071161118 \\
\hline 5 & 0,068317996 & 0,072334078 \\
\hline 6 & 0,070364989 & 0,072825063 \\
\hline 7 & 0,070046763 & 0,07276794 \\
\hline 8 & 0,074409478 & 0,074049469 \\
\hline 9 & 0,072299374 & 0,073332396 \\
\hline 10 & 0,075538539 & 0,074215606 \\
\hline
\end{tabular}

(Sumber Data Diolah 2019)

\subsection{Tabel Perhitungan}

Tabel 2. Perhitungan Single Life usia $x=35$ sd 44 dan $y=30$ sd 39 tahun

\begin{tabular}{|c|c|c|c|c|c|c|c|}
\hline$x$ & $q_{x}$ & $p_{x}$ & $l_{x}$ & $y$ & $q_{y}$ & $p_{y}$ & $l_{y}$ \\
\hline 35 & 0,00091 & 0,99909 & 97389,85 & 30 & 0,00054 & 0,99946 & 98681,91 \\
& & & & & & & \\
\hline 36 & 0,00099 & 0,99901 & 97301,22 & 31 & 0,00057 & 0,99943 & 98628,62 \\
$\cdot$ & $\cdot$ & $\cdot$ & $\cdot$ & $\cdot$ & $\cdot$ & $\cdot$ & $\cdot$ \\
$\cdot$ & $\cdot$ & $\cdot$ & $\cdot$ & $\cdot$ & $\cdot$ & $\cdot$ & $\cdot$ \\
\hline$\cdot$ & $\cdot$ & $\cdot$ & $\cdot$ & $\cdot$ & $\cdot$ & $\cdot$ & $\cdot$ \\
\hline 44 & 0,00279 & 0,99721 & 95897,39 & 39 & 0,00114 & 0,99886 & 97974,66 \\
\hline
\end{tabular}

(Sumber: Biro Pusat Aktuaria)

Untuk mendapat nilai pada baris pertama $p_{x}$ dan $p_{y}$, didapatkan dengan menggunakan persamaan $p_{35}=1-q_{35}$ dan $p_{30}=1-q_{30}$, sehingga diperoleh nilai,

$p_{x}=1-0,99909=0,00091$. dan

$p_{y}=1-0,99946=0,00054$,

Selanjutnya dilanjutkan dengan membuat nilai tabel mortalitas joint life.
Tabel 3. Tabel Mortalitas Joint Life usia $x=$ 35 sd 44 dan $y=30$ sd 39 tahun

\begin{tabular}{|l|l|l|}
\hline \multicolumn{1}{|c|}{$(\boldsymbol{x}, \boldsymbol{y})$} & \multicolumn{1}{|c|}{$\boldsymbol{p}_{\boldsymbol{x}, \boldsymbol{y}}$} & \multicolumn{1}{c|}{$\boldsymbol{q}_{\boldsymbol{x}, \boldsymbol{y}}$} \\
\hline$(35,30)$ & 0,99855 & 0,00145 \\
\hline$(36,31)$ & 0,998441 & 0,001559 \\
\hline$(37,32)$ & 0,998311 & 0,001689 \\
\hline$(38,33)$ & 0,998181 & 0,001819 \\
\hline$(39,34)$ & 0,998011 & 0,001989 \\
\hline$\cdot$ & & \\
$\cdot$ & & \\
\hline & & \\
\hline$(44,39)$ & 0,996073 & 0,003927 \\
\hline
\end{tabular}

(Sumber Data Diolah 2019)

Untuk mendapatkan nilai pada baris pertama yaitu,

$$
p_{35,30}=0,99909 \cdot 0,99946=0,99855
$$

$q_{35,30}=1-p_{30,35}=0,00145$

Setelah melengkapi perhitungan tabel mortalitas joint life, dilakukan perhitungan premi asuransi joint life dengan tingkat suku bunga mengikuti model Vasicek dan CIR.

\subsection{Nilai Tunai Manfaat Model Vasicek dan CIR}

Nilai tunai manfaat model vasicek dihitung sebagai berikut:

$$
\begin{aligned}
A_{x y: n}^{1}= & \sum_{k=0}^{n-1} P_{\text {vas }}(k+1)\left({ }_{k} p_{x y}-{ }_{k+1} p_{x y}\right) \\
A_{35,30: 10}^{1}= & P_{\text {vas }}(1)\left({ }_{0} p_{35,30}-{ }_{1} p_{35,30}\right) \\
& +P_{\text {vas }}(2)\left({ }_{1} p_{35,30}-{ }_{2} p_{35,30}\right) \\
& +\cdots+P_{\text {vas }}(10)\left({ }_{9} p_{35,30}\right. \\
& \left.-{ }_{10} p_{35,30}\right) \\
= & 0,93725323(1-0,99855049) \\
& +0,87979054(0,99855049 \\
& -0,996993316+\cdots \\
& +0,53230018(0,98104953 \\
& -0,977618367) \\
= & 0,015271731
\end{aligned}
$$

Nilai tunai manfaat model $C I R$ sebagai berikut:

$$
\begin{aligned}
A_{x y: n}^{1}= & \sum_{k=0}^{n-1} P_{c i r}(k+1)\left({ }_{k} p_{x y}-{ }_{k+1} p_{x y}\right) \\
A_{35,30: 10}^{1}= & P_{c i r}(1)\left({ }_{0} p_{35,30}-{ }_{1} p_{35,30}\right) \\
& +P_{c i r}(2)\left({ }_{1} p_{35,30}-{ }_{2} p_{35,30}\right) \\
& +\cdots+P_{c i r}(10)\left({ }_{9} p_{35,30}\right. \\
& \left.-{ }_{10} p_{35,30}\right) \\
= & 0,932454057(1-0,998550491) \\
& +0,867092258-0,996993316) \\
& +\cdots+0,483618378(0,98104953 \\
& -0,977618367)
\end{aligned}
$$




$$
=0,014488325
$$

Untuk hasil perhitungan yang lebih lengkap disajikan pada tabel 4 .

Tabel 4. Nilai Tunai Manfaat Model Vasicek dan $C I R$

\begin{tabular}{|c|c|c|}
\hline $\mathbf{x , y}$ & A vasicek $_{x y: 10}^{1}$ & $A^{1}$ CIR $_{x y: 10}^{1}$ \\
\hline 35,30 & 0.015271731 & 0.014488325 \\
\hline 36,31 & 0.016883679 & 0.016010654 \\
\hline 37,32 & 0.018754476 & 0.017777989 \\
\hline 38,33 & 0.020926401 & 0.019830172 \\
\hline 39,34 & 0.023458183 & 0.022224411 \\
\hline 40,35 & 0.026362271 & 0.024972937 \\
\hline 41,36 & 0.029677036 & 0.028111729 \\
\hline 42,37 & 0.033413809 & 0.031648927 \\
\hline 43,38 & 0.037631351 & 0.035641468 \\
\hline 44,39 & 0.042369949 & 0.040131303 \\
\hline
\end{tabular}

\subsection{Nilai Tunai Anuitas Model Vasicek dan} CIR

Nilai tunai anuitas model vasicek dihitung sebagai berikut:

$$
\begin{aligned}
& \quad \ddot{a}_{x y: n} \\
\ddot{a}_{35,30: 10} & \sum_{k=0}^{n-1} P_{\text {vas }}(k)_{k} p_{x y} \\
& P_{\text {vas }}(0){ }_{0} p_{35,30}+P_{\text {vas }}(1){ }_{1} p_{35,30} \\
& +\cdots+P_{\text {vas }}(9){ }_{9} p_{35,30} \\
= & 1 \times 1+0,93725323 \\
& \times 0,998550491+\cdots \\
& +0,5668016 \times 0,98104953 \\
= & 7,589956343
\end{aligned}
$$

Selanjutnya dihitung nilai tunai anuitas model CIR sebagai berikut:

$$
\begin{gathered}
\ddot{a}_{x y: n}=\sum_{k=0}^{n-1} P(k)_{k} p_{x y} \\
\ddot{a}_{35,30: 10}=P_{c i r}(0){ }_{0} p_{35,30}+P_{\text {cir }}(1){ }_{1} p_{35,30} \\
+\cdots+P_{\text {cir }}(9){ }_{9} p_{35,30} \\
=1 \times 1+0,932454057 \\
\times 0,998550491+\cdots \\
+0,520235652 \times 0,98104953 \\
=7,328968194
\end{gathered}
$$

Untuk hasil perhitungan yang lebih lengkap disajikan pada tabel 5 .
Tabel 5. Nilai Tunai Anuitas Model Vasicek dan $C I R$

\begin{tabular}{|c|c|c|}
\hline $\mathrm{x}, \mathrm{y}$ & $\ddot{a}$ Vasicek $_{x, y: 10}$ & $\ddot{a}$ CIR $_{x, y: 10}$ \\
\hline 35,30 & 7.589956343 & 7.328968194 \\
\hline 36,31 & 7.584685159 & 7.324004023 \\
\hline 37,32 & 7.578521414 & 7.31819869 \\
\hline 38,33 & 7.571337682 & 7.311431927 \\
\hline 39,34 & 7.56280898 & 7.303393255 \\
\hline 40,35 & 7.552848908 & 7.294001673 \\
\hline 41,36 & 7.541355564 & 7.283160921 \\
\hline 42,37 & 7.5284848 & 7.271024655 \\
\hline 43,38 & 7.513924723 & 7.25729747 \\
\hline 44,39 & 7.49722236 & 7,26044119 \\
\hline
\end{tabular}

(Sumber Data Diolah 2019)

\subsection{Perhitungan Premi Asuransi Joint Life dengan Model Vasicek dan CIR.}

Perhitungan nilai premi asuransi joint life model vasicek dan CIR dengan uang pertanggungan $\quad R p .100 .000 .000,00$ dihitung menggunakan persamaan sebagai berikut:

$$
\begin{aligned}
P_{\text {vas }}= & \frac{A_{x y: n}^{1}}{\ddot{a}_{x y: n}} \cdot 100000000 \\
& =\frac{A_{35,30: 10}^{1}}{\ddot{a}_{35,30: 10}} \cdot 100000000 \\
& =\frac{0.014488325}{7 \cdot 589956343} \cdot 100000000 \\
& =\text { Rp. } 201 \cdot 210,00 \\
P_{\text {cir }}= & \frac{A_{x y: n}^{1}}{\ddot{a}_{x y: n}} \cdot 100000000 \\
= & \frac{A_{35,30: 10}^{1}}{\ddot{a}_{35,30: 10}} \cdot 100000000 \\
= & \frac{0.014488325}{7.328968194} \cdot 100000000 \\
= & \text { Rp. } 197 \cdot 686,00
\end{aligned}
$$

Sehingga diperoleh hasil perhitungannya disajikan pada tabel 6 .

Tabel 6. Premi Asuransi Joint Life dengan Model Vasicek dan CIR.

\begin{tabular}{|c|c|cc|}
\hline $\mathbf{x , y}$ & \multicolumn{2}{|c|}{ Premi Vasicek } & \multicolumn{2}{c|}{ Premi CIR } \\
\hline 35,30 & $\mathrm{Rp} 201.209,00$ & $\mathrm{Rp}$ & $197.685,00$ \\
\hline 36,31 & $\mathrm{Rp} 222.602,00$ & $\mathrm{Rp}$ & $218.605,00$ \\
\hline 37,32 & $\mathrm{Rp} 247.468,00$ & $\mathrm{Rp}$ & $242.928,00$ \\
\hline 38,33 & $\mathrm{Rp} 276.389,00$ & $\mathrm{Rp}$ & $271.221,00$ \\
\hline 39,34 & $\mathrm{Rp} 310.178,00$ & $\mathrm{Rp}$ & $304.302,00$ \\
\hline 40,35 & $\mathrm{Rp} 349.037,00$ & $\mathrm{Rp}$ & $342.376,00$ \\
\hline 41,36 & $\mathrm{Rp} 393.523,00$ & $\mathrm{Rp}$ & $385.982,00$ \\
\hline 42,37 & $\mathrm{Rp} 443.831,00$ & $\mathrm{Rp}$ & $435.274,00$ \\
\hline 43,38 & $\mathrm{Rp} 500.821,00$ & $\mathrm{Rp}$ & $491.112,00$ \\
\hline 44,39 & $\mathrm{Rp} 565.142,00$ & $\mathrm{Rp}$ & $554.181,00$ \\
\hline
\end{tabular}

(Sumber Data Diolah 2019) 


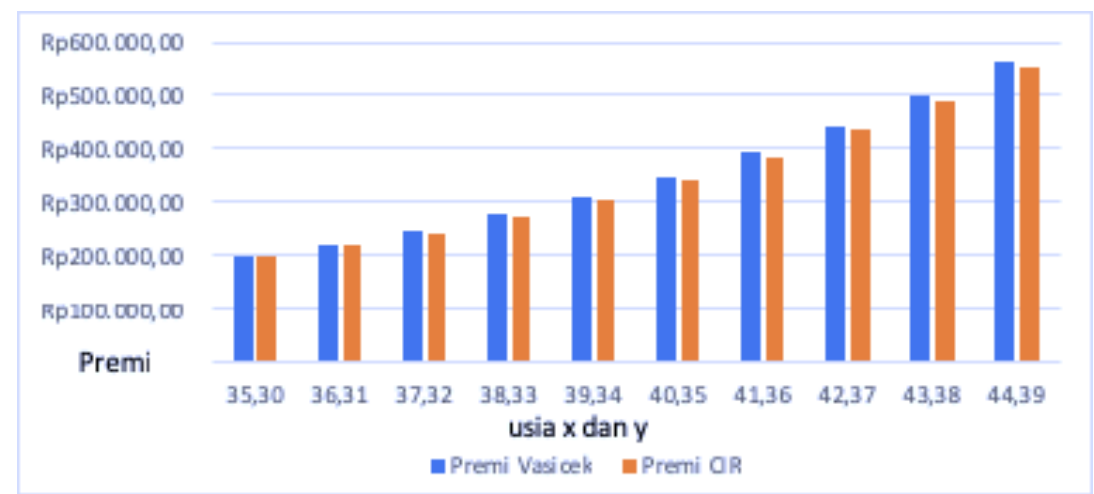

Gambar 1. Perbandingan nilai premi Vasicek dan CIR.

Untuk melihat lebih jelas hasil pada tabel 6, disajikan dalam bentuk grafik pada gambar 1 . Gambar 1 menunjukan bahwa nilai premi asuransi jiwa joint life dengan usia tertanggung 35 tahun dan 30 tahun dengan lamanya kontrak 10 tahun menggunakan model Vasicek dan CIR mengalami peningkatan hingga akhir tahun kontrak, dan diketahui bahwa model Vasicek lebih mahal dari $C I R$.

\section{SIMPULAN DAN SARAN}

Berdasarkan kontrak dalam penelitian ini, nilai premi asuransi jiwa joint life dengan usia tertanggung $x=35$ dan $y=30$ tahun dengan

\section{DAFTAR PUSTAKA}

Bayazit, D. 2004. Yield Curve Estimation and Prediction with Vasicek Model. The Midldle East Technical University, Ankara.

Cox J. C., Ingersoll J. E., and Ross S. A. 1985. "A Theory of The Term Structure of Interest Rates". Econometrica Vol. 53, Issue 2, pp.385-408.

Futami, T. (1993). Matematika Asuransi Jiwa, Bagian I. Tokyo: Oriental Life Insurance Cultural Development Center. lamanya kontrak 10 tahun dengan uang pertanggungan Rp.100.000.000,00, menggunakan model Vasicek adalah Rp.201.210,00 sedangkan dengan model CIR adalah sebesar Rp.197.686,00. Nilai premi asuransi jiwa joint life dengan menggunakan model Vasicek relatif lebih mahal dibandingkan dengan harga premi asuransi jiwa joint life dengan menggunakan model $C I R$.

Disarankan untuk penelitian selanjutnya dapat menghitung nilai premi produk asuransi dengan model tingkat suku bunga yang berbeda dan juga diharapkan dapat memperhitungkan faktor biayanya dalam menghitung premi.

Hull, J.C. 2003. Option, Future, and Other Derivatives. USA: Prentice Hall.

Mariana, E., Erna, A., \& Sentot, D, S. 2015. "Estimasi Parameter pada Model Suku Bunga Cox Ingersoll Ross (CIR) Menggunakan Kalman Filter untuk Menentukan Harga Zero Coupon Bond". Jurnal Sains dan Seni, ITS.Surabaya: FIMPA Institut Teknologi Sepuluh Nopember.

Zeytun, S., 2007. A Comparative Study of the Vasicek and the CIR Model of the Short Rate. Germany: Fraunhofer: Institut fur Techno- und Wirtschaftsmathematik. 
Lampiran 1. Estimasi Parameter Suku Bunga Bank Indonesia

\begin{tabular}{|c|c|c|c|c|c|c|c|}
\hline Tanggal & Bunga & $\begin{array}{c}\text { Bunga } \\
\left(r_{t}\right)\end{array}$ & $\mathrm{t}$ & $r_{(t+1)}$ & $1 / r_{t}$ & $r_{(t+1)} / r_{t}$ & $\left(\left(r_{(t+1)}-r_{t}\right) / \operatorname{sqrt}\left(r_{t}\right)-\text { teta/sqrt }\left(r_{t}\right)+\mathrm{K}^{*} \operatorname{sqrt}\left(r_{t}\right)\right)^{\wedge} 2$ \\
\hline 13-Jun-13 & $6,00 \%$ & 0,06 & 1 & 0,065 & 16,666667 & 1,083333 & 0,065799097 \\
\hline 11-Jul-13 & $6,50 \%$ & 0,065 & 2 & 0,065 & 15,384615 & 1 & 0,072822709 \\
\hline 15-Agu-13 & $6,50 \%$ & 0,065 & 3 & 0,07 & 15,384615 & 1,076923 & 0,08379198 \\
\hline 29-Agu-13 & $7,00 \%$ & 0,07 & 4 & 0,0725 & 14,285714 & 1,035714 & 0,0966856886 \\
\hline 12-Sep-13 & $7,25 \%$ & 0,0725 & 5 & 0,0725 & 13,793103 & 1 & 0,100246084 \\
\hline 08-Okt-13 & $7,25 \%$ & 0,0725 & 6 & 0,075 & 13,793103 & 1,034483 & 0,106211714 \\
\hline $12-N o v-13$ & $7,50 \%$ & 0,075 & 7 & 0,075 & 13,333333 & 1 & 0,10977223 \\
\hline 12-Des-13 & $7,50 \%$ & 0,075 & 8 & 0,075 & 13,333333 & 1 & 0,10977223 \\
\hline 09-Jan-14 & $7,50 \%$ & 0,075 & 9 & 0,075 & 13,333333 & 1 & 0,10977223 \\
\hline 13-Feb-14 & $7,50 \%$ & 0,075 & 10 & 0,075 & 13,333333 & 1 & 0,10977223 \\
\hline 13-Mar-14 & $7,50 \%$ & 0,075 & 11 & 0,075 & 13,333333 & 1 & 0,10977223 \\
\hline 08-Apr-14 & $7,50 \%$ & 0,075 & 12 & 0,075 & 13,333333 & 1 & 0,10977223 \\
\hline 08-Mei-14 & $7,50 \%$ & 0,075 & 13 & 0,075 & 13,333333 & 1 & 0,10977223 \\
\hline 12-Jun-14 & $7,50 \%$ & 0,075 & 14 & 0,075 & 13,333333 & 1 & 0,10977223 \\
\hline 10-Jul-14 & $7,50 \%$ & 0,075 & 15 & 0,075 & 13,333333 & 1 & 0,10977223 \\
\hline 14-Agu-14 & $7,50 \%$ & 0,075 & 16 & 0,075 & 13,333333 & 1 & 0,10977223 \\
\hline 11-Sep-14 & $7,50 \%$ & 0,075 & 17 & 0,075 & 13,333333 & 1 & 0,10977223 \\
\hline 07-Okt-14 & $7,50 \%$ & 0,075 & 18 & 0,075 & 13,333333 & 1 & 0,10977223 \\
\hline 13-Nov-14 & $7,50 \%$ & 0,075 & 19 & 0,0775 & 13,333333 & 1,033333 & 0,115904591 \\
\hline 18-Nov-14 & $7,75 \%$ & 0,0775 & 20 & 0,0775 & 12,903226 & 1 & 0,119459836 \\
\hline 11-Des-14 & $7,75 \%$ & 0,0775 & 21 & 0,0775 & 12,903226 & 1 & 0,119459836 \\
\hline 15-Jan-15 & $7,75 \%$ & 0,0775 & 22 & 0,075 & 12,903226 & 0,967742 & 0,11333279 \\
\hline 17-Feb-15 & $7,50 \%$ & 0,075 & 23 & 0,075 & 13,333333 & 1 & 0,10977223 \\
\hline 17-Mar-15 & $7,50 \%$ & 0,075 & 24 & 0,075 & 13,333333 & 1 & 0,10977223 \\
\hline 14-Apr-15 & $7,50 \%$ & 0,075 & 25 & 0,075 & 13,333333 & 1 & 0,10977223 \\
\hline 19-Mei-15 & $7,50 \%$ & 0,075 & 26 & 0,075 & 13,333333 & 1 & 0,10977223 \\
\hline 18-Jun-15 & $7,50 \%$ & 0,075 & 27 & 0,075 & 13,333333 & 1 & 0,10977223 \\
\hline 14-Jul-15 & $7,50 \%$ & 0,075 & 28 & 0,075 & 13,333333 & 1 & 0,10977223 \\
\hline 18-Agu-15 & $7,50 \%$ & 0,075 & 29 & 0,075 & 13,333333 & 1 & 0,10977223 \\
\hline 17-Sep-15 & $7,50 \%$ & 0,075 & 30 & 0,075 & 13,333333 & 1 & 0,10977223 \\
\hline $15-O k t-15$ & $7,50 \%$ & 0,075 & 31 & 0,075 & 13,333333 & 1 & 0,10977223 \\
\hline 17-Nov-15 & $7,50 \%$ & 0,075 & 32 & 0,075 & 13,333333 & 1 & 0,10977223 \\
\hline 17-Des-15 & $7,50 \%$ & 0,075 & 33 & 0,0725 & 13,333333 & 0,966667 & 0,103806535 \\
\hline 14-Jan-16 & $7,25 \%$ & 0,0725 & 34 & 0,07 & 13,793103 & 0,965517 & 0,094452868 \\
\hline $18-F e b-16$ & $7,00 \%$ & 0,07 & 35 & 0,0675 & 14,285714 & 0,964286 & 0,08529028 \\
\hline 17-Mar-16 & $6,75 \%$ & 0,0675 & 36 & 0,0675 & 14,814815 & 1 & 0,081749933 \\
\hline 21-Apr-16 & $6,75 \%$ & 0,0675 & 37 & 0,0675 & 14,814815 & 1 & 0,081749933 \\
\hline 19-Mei-16 & $6,75 \%$ & 0,0675 & 38 & 0,0675 & 14,814815 & 1 & 0,081749933 \\
\hline 16 -Jun-16 & $6,75 \%$ & 0,0675 & 39 & 0,065 & 14,814815 & 0,962963 & 0,076340004 \\
\hline 21-Jul-16 & $6,50 \%$ & 0,065 & 40 & 0 & 15,384615 & 0 & 0,000222185 \\
\hline
\end{tabular}

